\title{
Total Lymphoid Irradiation
}

National Cancer Institute

\section{Source}

National Cancer Institute. Total Lymphoid Irradiation. NCI Thesaurus. Code C156721.

The use of extensive lymphatic irradiation to achieve immunosuppression. The irradiated areas includ the cervical, supraclavicular, and axillary lymph nodes, and the mediastinal region, as well as the the porta hepatis, celiac nodes, splenic pedicle and spleen, and paraaortic, iliac, inguinal, and femoral nodes. 